\title{
POWER SPECTRAL ANALYSIS OF RESIDUAL AEROMAGNETIC MAP OF SOKOTO BASIN, NORTH WESTERN NIGERIA
}

\author{
${ }^{1}$ Ezeh, O. C., ${ }^{2}$ Egwuonwu, G. N., ${ }^{3}$ Iyoha A. and ${ }^{4}$ Umego, M. N.
}

1. Nigeria Geological Survey Agency, Utako, Abuja, FCT, Nigeria tediksglobalservices@gmail.com

2. Department of Physics and Industrial Physics, Nnamdi Azikiwe University, Awka, Anambra State, Nigeria gn.egwuonwu@unizik.edu.ng

3. Department of Physics, Faculty of Physical Sciences, Ambrose Alli University, Ekpoma, Edo State, Nigeria iyoha_abraham@aauekpoma.edu.ng

4. Department of Physics, Chukwemeka Odimegwu Ojukwu University, Uli, Awka, Anambra State, Nigeria mn.umego@unizik.edu.ng

\begin{abstract}
Aeromagnetic data obtained from a recent aeromagnetic survey of Sokoto Basin, northwestern Nigeria has been studied using Power Spectral (PS) analysis. The Sokoto Basin is an arm of the Iullemmeden Basin is situated between latitudes $10^{\circ} 30^{\prime \prime} \mathrm{N}$ to $14^{\circ} 00^{\prime \prime} \mathrm{N}$ and longitudes $3^{\circ} 30^{\prime \prime}$ $\mathrm{E}$ to $7^{\circ} 00^{\prime \prime} \mathrm{E}$ in the Nigeria national grid. The PS analysis was carried out to determine the depth to magnetic sources in the Basin. By splitting the study area into 16 spectral model blocks, the spectral probe of 27.5 by $27.5 \mathrm{~km}^{2}$ for each block was carried out respectively. The results of the PS analysis revealed two prominent magnetic source depth layers. Depths determination of the magnetic sources showed that the first layer has average depth of $0.28 \mathrm{~km}$ which is interpreted as shallow magnetic zones attributed to the intrusions of magnetic rocks into the sedimentary formation. The second layer has average depth of $1.86 \mathrm{~km}$ and was interpreted as the deep magnetic source representing the depth to magnetic basement. Hence the results show that the maximum thickness of the sedimentary layers to be $1.86 \mathrm{~km}$ is the limit of the depressions on the basement surface of the basin. Hence it suggests that exploration of hydrocarbon which would require a minimum sedimentary thickness of about $2.3 \mathrm{~km}$ as obtainable in the coasts of West Africa region is also not feasible.
\end{abstract}

Keywords: Power Spectral, Aeromagnetic, Sedimentary, Basement, Hydrocarbon 


\section{Introduction}

Plausible analysis of the Earth's subsurface has been a matter of interest in geosciences and over the years, multiple researches have been carried out to unravel its complexities using geophysical methods. The major concern in the researches remains the suspected areas of abundant mineral deposits especially characterized hydrocarbon potentials. Particularly, within various sedimentary basins of the Earth, the major aim boils down to the delineation and exploration economic resources such as crude oil. With the advances in technology and the need to have a clearer picture of the subsurface, analysis of how the earth interior varies both vertically and laterally to aid meaningful interpretation of geological structures is ensured (Dobrin, 1981). Geophysical methods such as magnetic, seismic, resistivity, electrical, potential field, well logging, gravity, radiometric, thermal were found useful for detecting discontinuities, faults, joints and other basement structures (Cordell and Grouch, 1985). However, for the purpose of this study, we shall be using the magnetic method of geophysical survey aided by power spectral analysis (PS). The procedure of PS is based on a method developed by Spector and Grant (1970) wherein the characteristics of the residual magnetic field are studied by first transforming the data from the space to the wave number domain and then analyzing their frequency characteristics. Fourier Transform is commonly used for the transformation hence, potential field anomalies (gravity and magnetic) could be represented by a one or two-dimensional Fourier Transform consisting of various frequencies, which characterize the anomalies (Nwogbo, 1987). A logarithmic plot of the power spectrum versus frequency on a linear scale to show a series of points that may well be represented by bodies occurring within a particular depth range, which fall on one or straight line segments whose slopes provide a measure of the mean depth to the ensemble of anomalous bodies (Spector and Grant, 1970).

\section{The Study Area}

The study area is the Sokoto Sedimentary Basin, in northwestern Nigeria (Figure1). The Sokoto Basin lies between longitudes $3^{\circ} 30^{\prime \prime} \mathrm{E}$ and $6^{\circ} 58^{\prime \prime} \mathrm{E}$ and between latitudes $10^{\circ} 30^{\prime \prime} \mathrm{N}$ to $14^{\circ} 00^{\prime \prime}$ $\mathrm{N}$ with an estimated area of $12,100 \mathrm{~km}^{2}$. It consists predominantly of a gently undulating plain with an average elevation varying from 250 to $400 \mathrm{~m}$ above mean sea-level. This plain is occasionally interrupted by low mesas. A low escarpment, known as the "Dange Scarp" is the most prominent feature in the basin and it is closely related to the geology. The Sokoto (Sedimentary) Basin forms the south-eastern segment of a large synclinal basin, the Iullemmeden basin. The Iullemmeden basin lies entirely within the Pan African province of West Africa; which encompasses parts of Algeria, Mali, and Republic of Benin and Niger. 


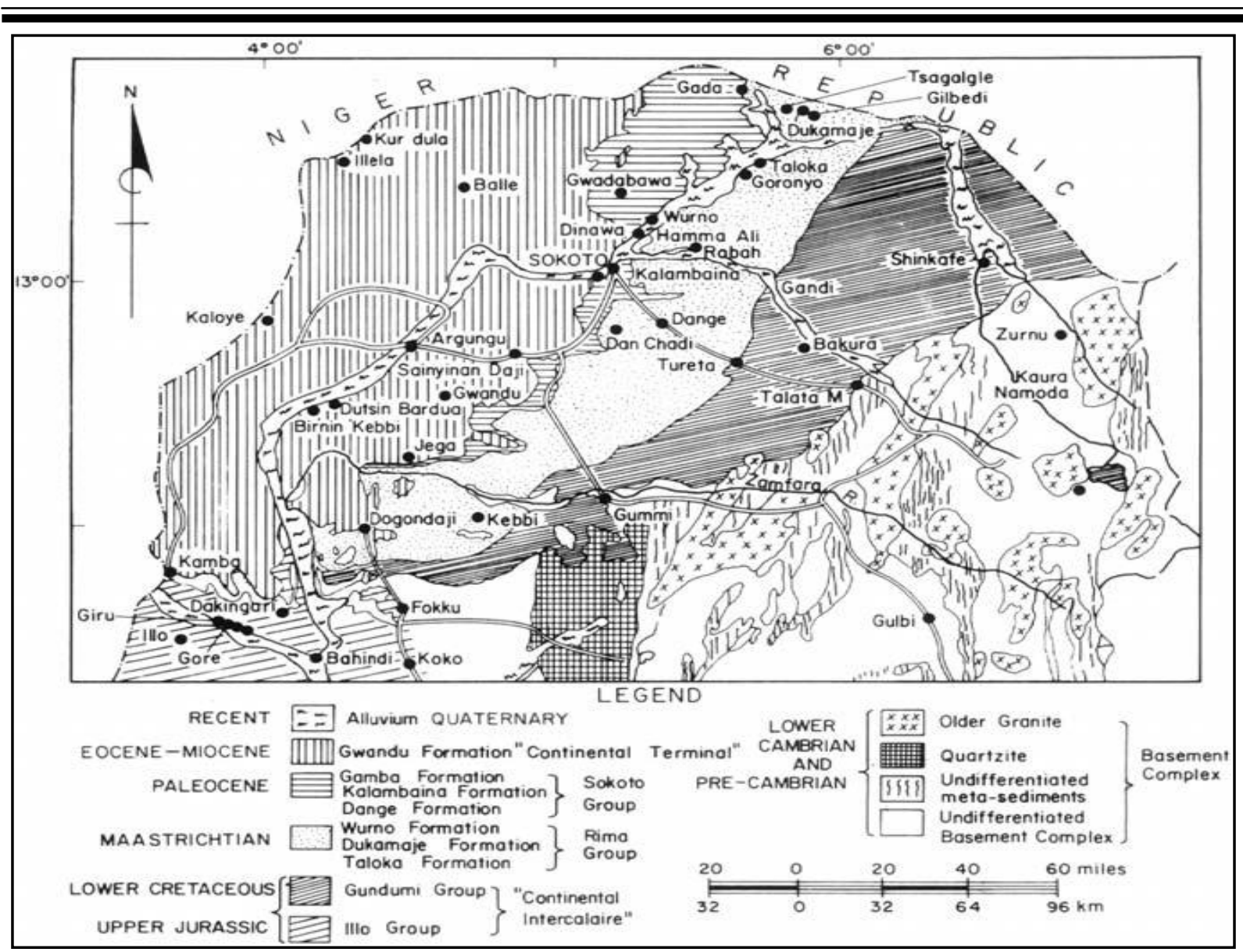

Figure 1: Geological Map of the Sokoto Basin (After Keary and Brooks, 1984)

\section{Methodology}

The aeromagnetic map sheets used for the analysis are the published maps by the Nigerian Geological Survey Agency (NGSA), then Geological Survey of Nigeria, which produced the aeromagnetic map of substantial part of Nigeria between 1974 and 1980. A software namely Geosoft Oasis Montaj of Patterson Grant and Watson (PGW) of Canada Geosoft's Oasis Montaj software was used for processing the aeromagnetic data while the Geosoft Executables (GX) software which was also developed by PGW was used for the imaging of the study area, map preparation and its interpretation. Four $0.5^{\circ} \times 0.5^{\circ}$ high resolution total field intensity aeromagnetic map namely; sheets 29 (Dange), 30 (Dandi), 51 (Gunmi), and 52 (Anka) in the Sokoto sedimentary basin of scale 1:100,000 were obtained from the Nigerian Geological Survey Agency (NGSA). The maps were digitized in . $g b d$ format and were merged into one data file. Then data reduction, removal of heading error and lag, compensation for errors and the removal of the effects of time varying external fields of the data were all carried out. International Geomagnetic Reference Field was used. The TMI map obtained (Figure 2) shows the effects of all subsurface magnetic sources. Thus, in order to unveil better the anomaly occurrences as may be caused by the basement rock; the TMI was superimposed on the regional field map (Figure 3) that comes from larger and deeper sources. The regional field was subtracted from the total magnetic field at grid cross points using the Butterworth filtering method as a set control file to filter out short wavelength components to obtain the residual anomalies (Figure 4). 


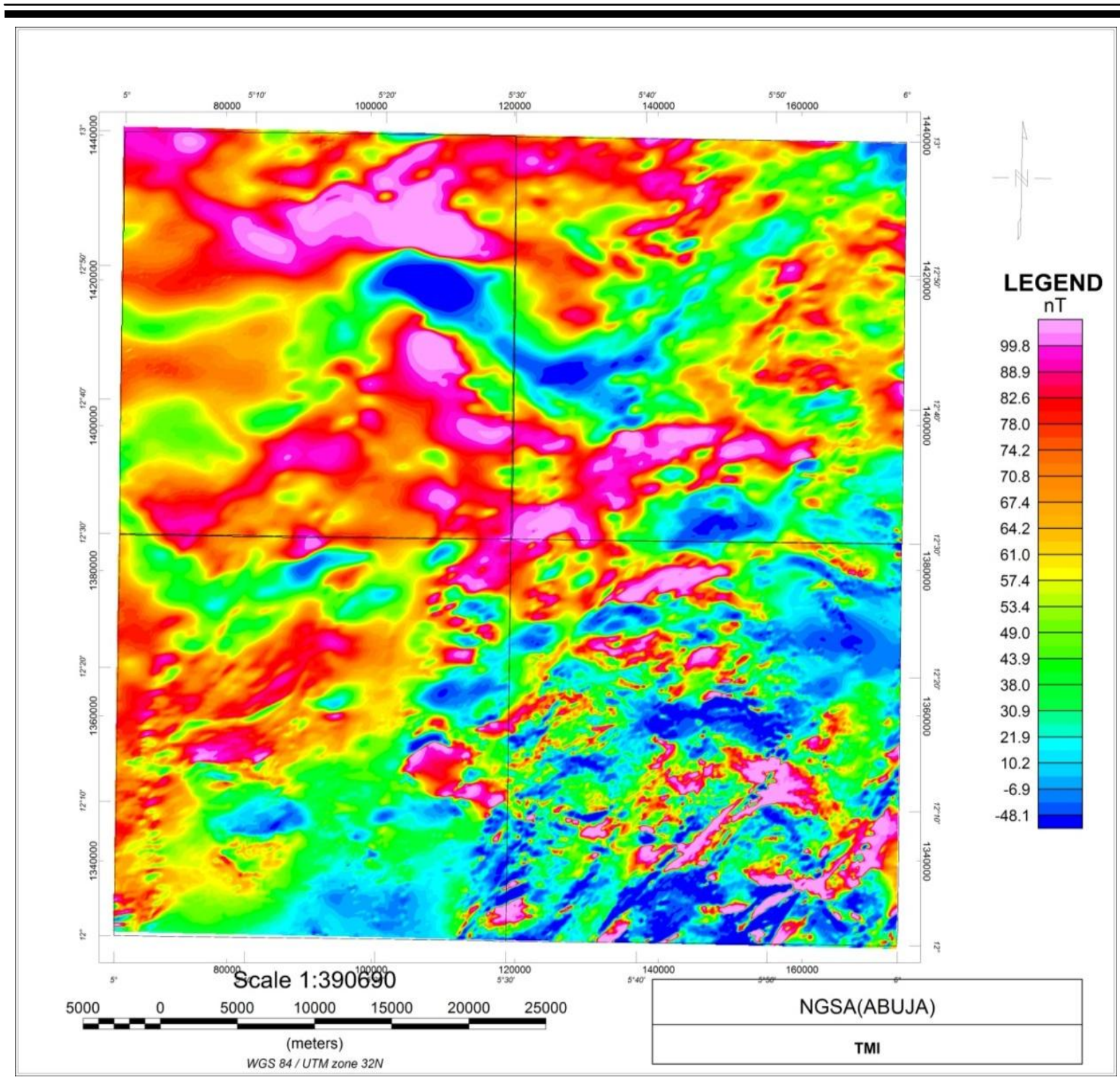

Figure 2: Total Magnetic Intensity (TMI) Map of the Study Area. 


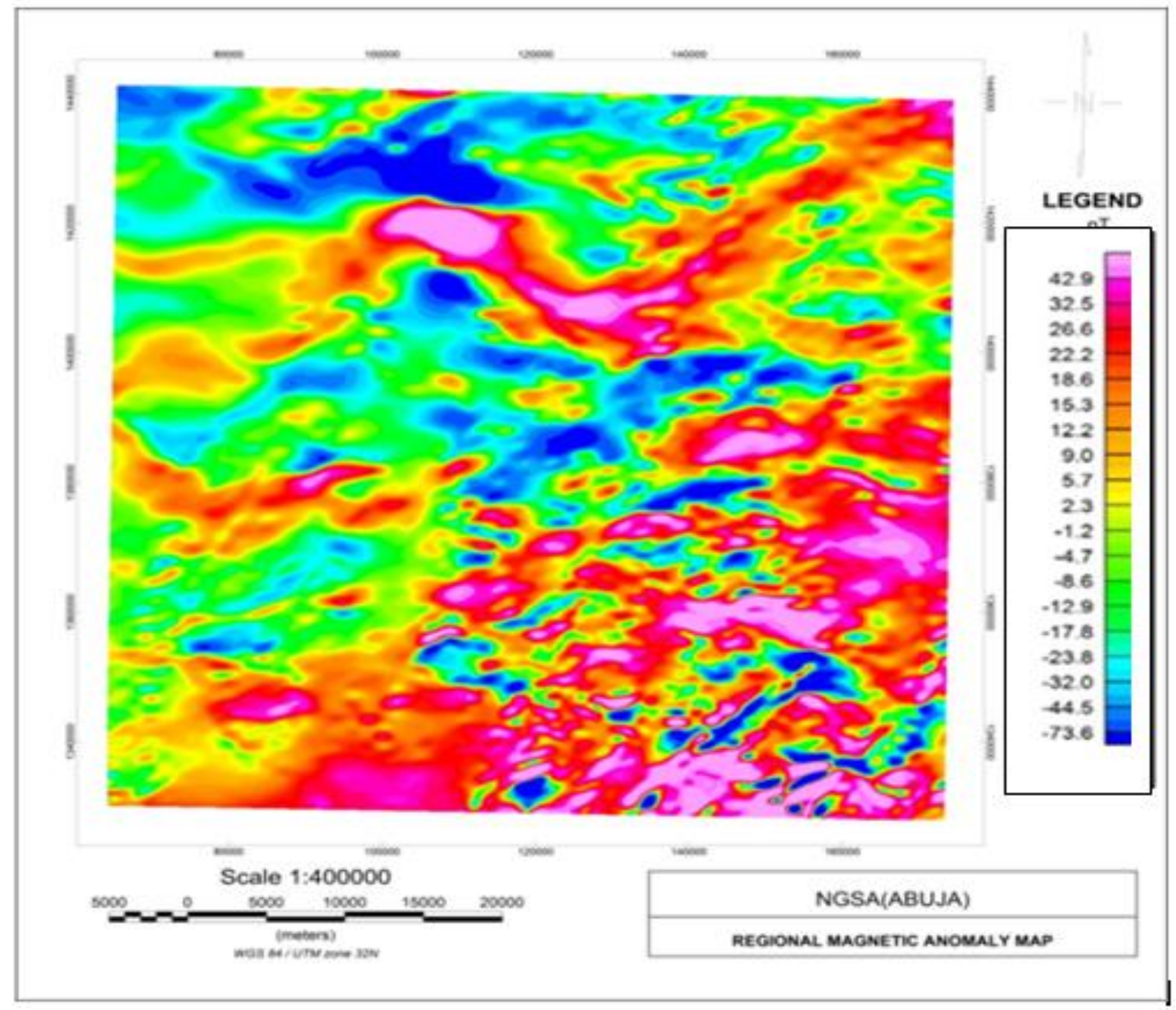

Figure 3: The regional map of the study area. 


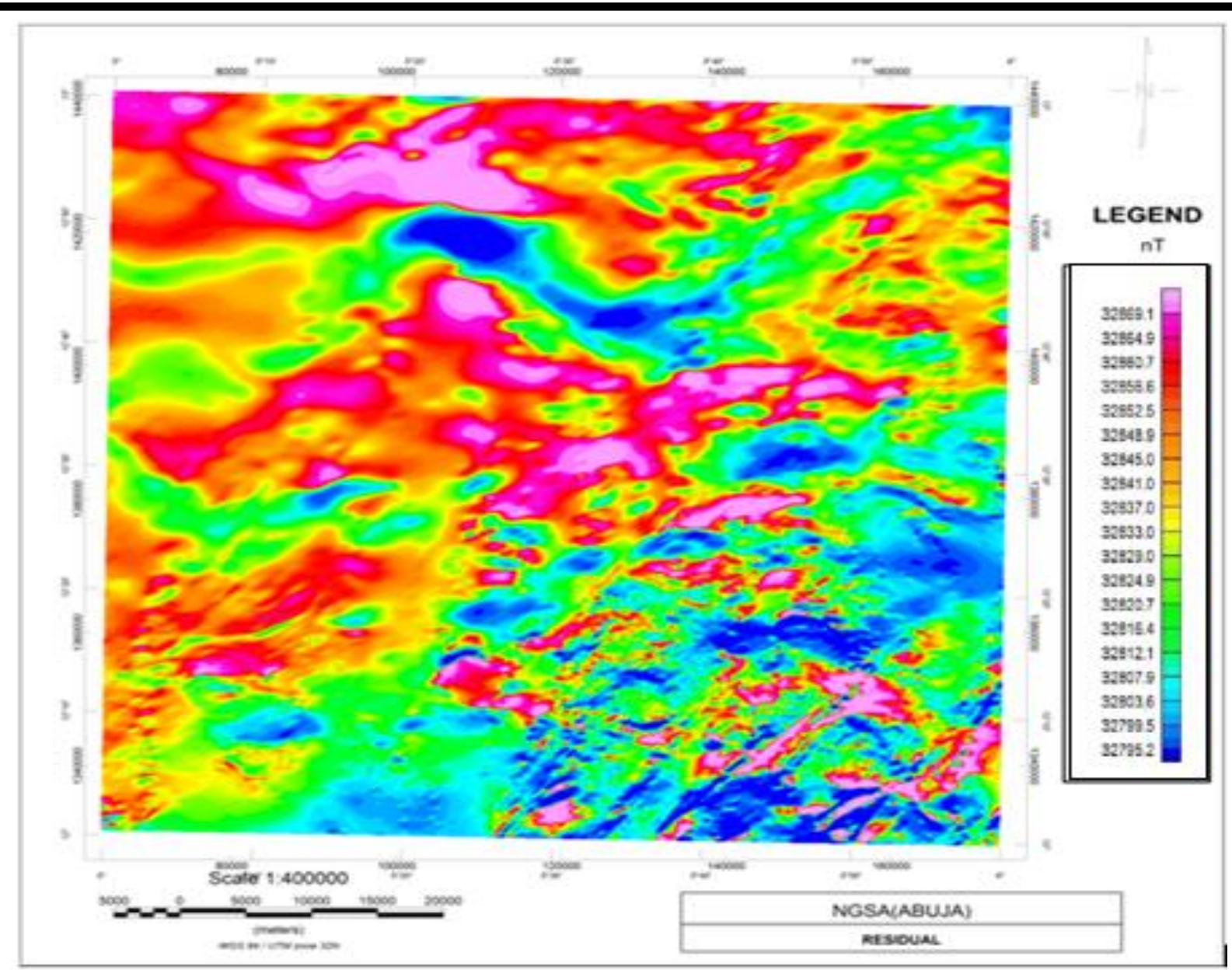

Figure 4: The Residual anomaly map of the study area.

The residual map of the study area was divided into sixteen (16) blocks of overlapping sections. Graphs of logarithms of the spectral energies against frequencies estimated for various blocks were obtained. Linear segment from low frequencies portion of the spectra, representing contributions from the deep seated causative bodies could be drawn from each graph. The gradient of the linear segment was evaluated and the equation 1 was used to calculate the depth to causative bodies. If $\mathrm{z}$ is the mean depth of a layer, the depth factor for this ensemble of anomalies is $e^{-2 z \rho}$. Thus, the logarithmic plot of the radial average power spectrum would give a straight line whose slope $m$ is $-2 z$. The mean depth of burial of the ensemble is thus given by:

$$
z=-\frac{m}{2}
$$

For the purpose of easier handling of the large data involved and the determination of the depths to magnetic layers using the spectral depth method, the four residual blocks of the study area were subdivided into sixteen spectral blocks (Figure 5). 


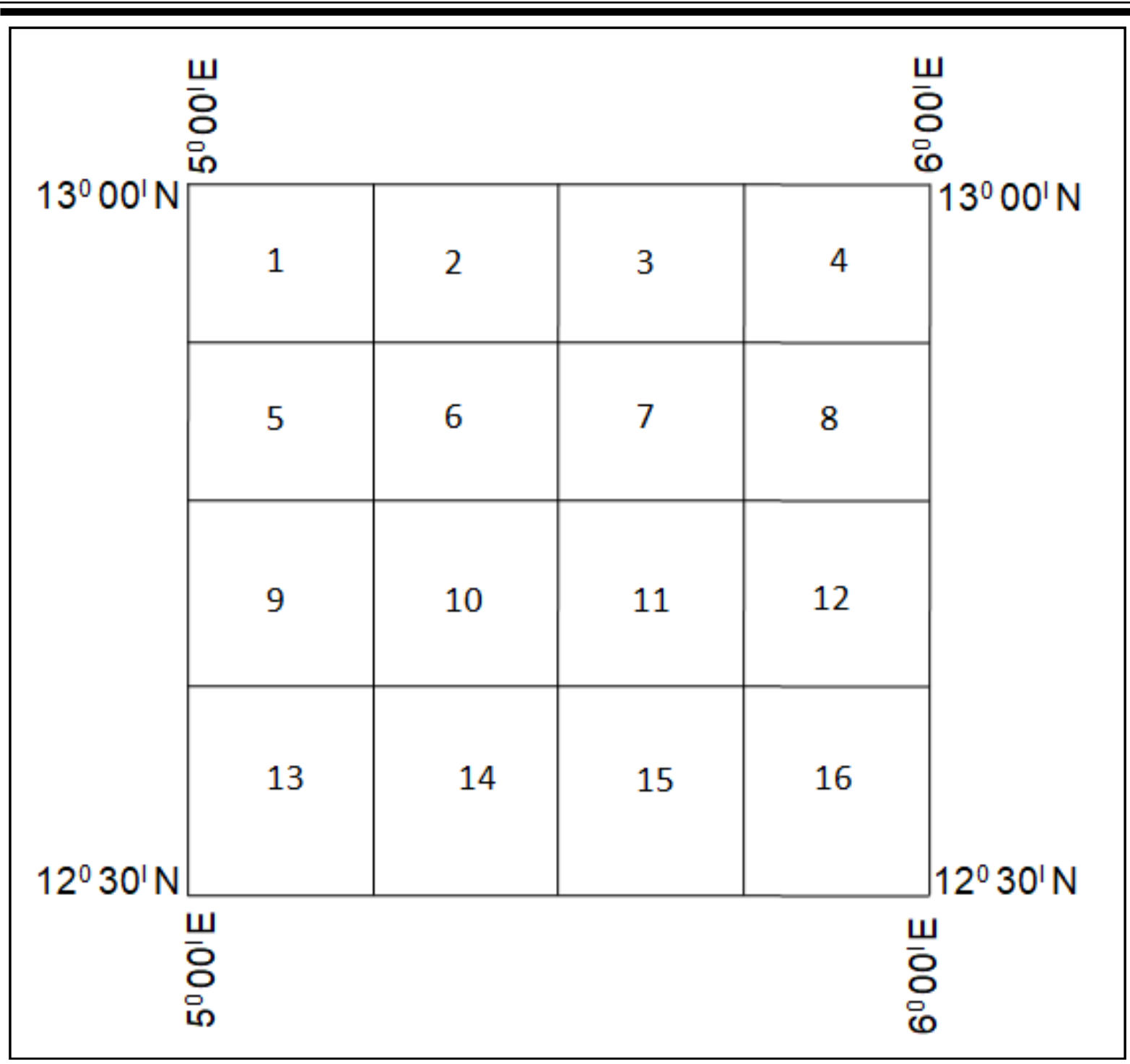

Figure 5: The sixteen blocks for spectral depth determination

\section{Results and Interpretation}

Two linear segments were observed in the lines of best fit were drawn which resulted into two and the gradient of each of the line segments were evaluated for the purpose of estimating the depths to the magnetic sources. Spectral method is based on the shape of the power spectrum for buried bodies. The process of mapping the depth to basement using a grid of magnetic data involves calculating the average grid to estimate depth. Oasis Montaj program employing the fast Fourier transform technique was used to transform the residual magnetic data into the radial energy spectrum for each block. After the calculation of the average radial power spectrum, the plot was displayed in a semi-long figure of amplitude versus frequency. These are shown in Figure 6. 
International Journal of Advanced Academic Research (Sciences, Technology and Engineering) | ISSN: 2488-9849 Vol. 7, Issue 1 (January, 2021)|www.ijaar.org

Journal DOI: 10.46654/ij.24889849

Article DOI: 10.46654/ij.24889849.e7122
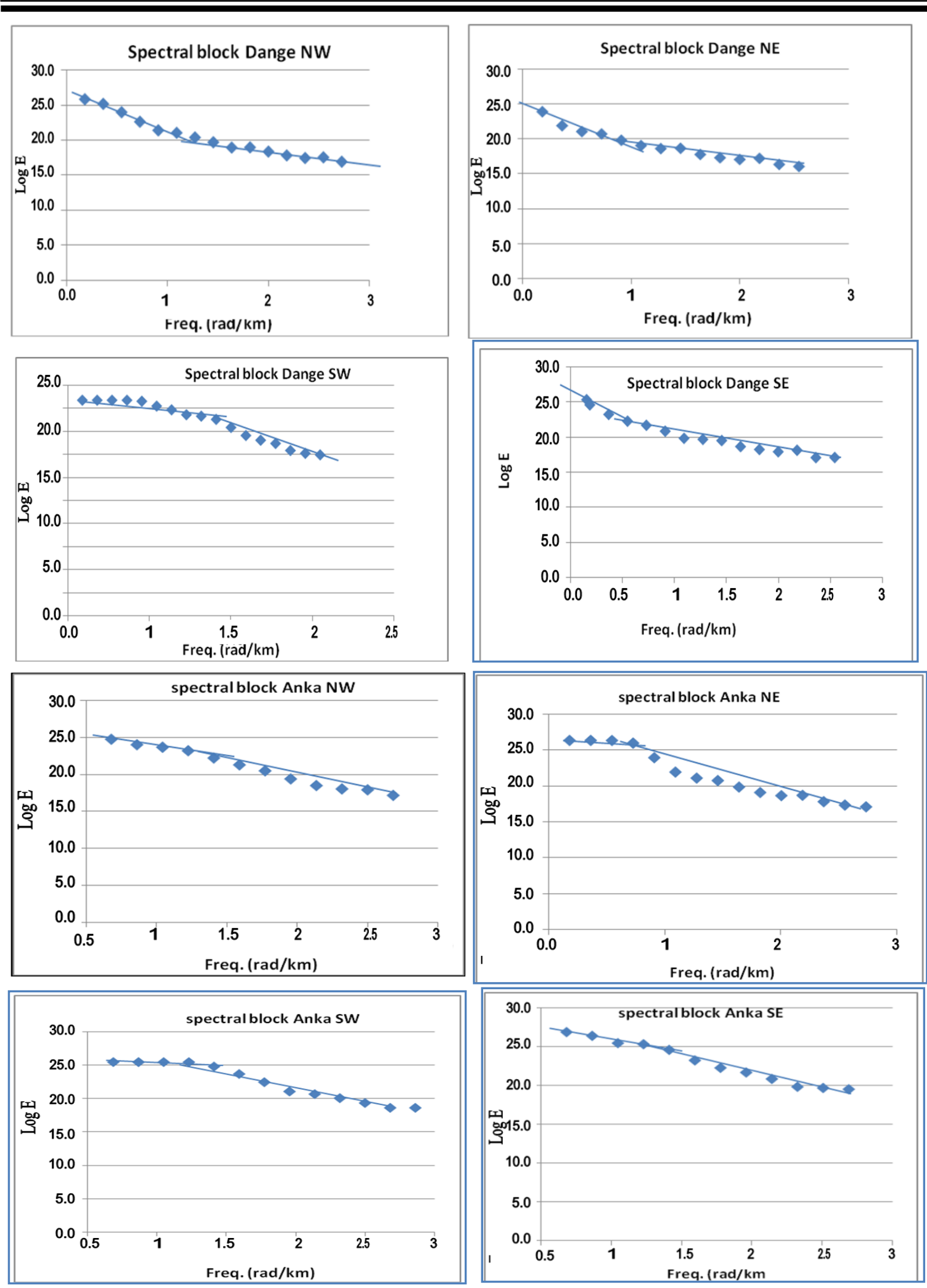
International Journal of Advanced Academic Research (Sciences, Technology and Engineering) | ISSN: 2488-9849 Vol. 7, Issue 1 (January, 2021)|www.ijaar.org

Journal DOI: 10.46654/ij.24889849

Article DOI: 10.46654/ij.24889849.e7122
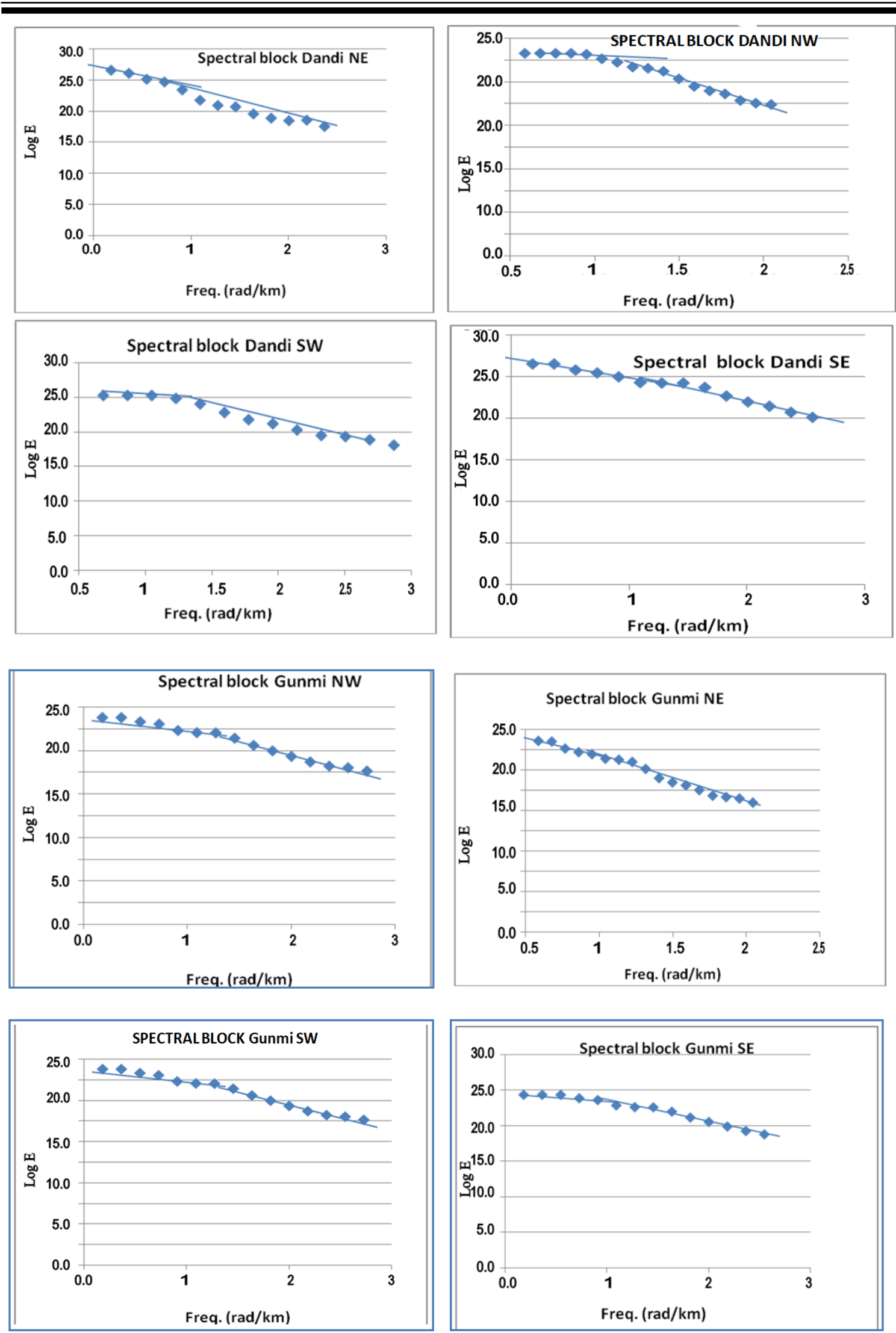

Figure 6: Graphs of the logarithm of some spectral energies against frequencies for the blocks. 
Finally, the depths were calculated for all the sixteen blocks using the slopes of the straight line segments using equation 1 for each block as shown in the Table 1 . It is of worthy of note that spectral depths are average depths in general and individual depth estimated may have values which differ from one another. The first layer depth which are the primary sources as derived from the statistical spectral analysis shown in table have an estimated depth ranging from 0.25 $\mathrm{km}-0.32 \mathrm{~km}$ with an average depth of $0.28 \mathrm{~km}$ are the magnetic rocks that intrude into the sedimentary formation. The second layer depths are the secondary sources which may be as result of magnetic rocks that are emplaced or intruded into the basement underlying the sedimentary basin. It therefore represents the depth to the underlying magnetic basement rock within the study area. It has an estimated depth ranging from $1.30 \mathrm{~km}$ to $2.30 \mathrm{~km}$ with an average depth of $1.80 \mathrm{~km}$.

Table 1: Depths estimates for the first and second magnetic layers for the sixteen spectral blocks and their Coordinates.

\begin{tabular}{|c|c|c|c|c|}
\hline \multirow{2}{*}{$\begin{array}{c}\text { SPECTRAL } \\
\text { BLOCKS }\end{array}$} & $\begin{array}{c}\text { LONGITUDE } \\
(\mathbf{X}) \\
\text { DEGREE }\end{array}$ & $\begin{array}{c}\text { LATTITUDE } \\
(\mathbf{Y}) \\
\text { DEGREE }\end{array}$ & $\begin{array}{c}\text { DEEP } \\
\text { SOURCES } \\
\left(\mathbf{Z}_{\mathbf{1}}\right) \mathbf{K m}\end{array}$ & $\begin{array}{c}\text { SHALLOW } \\
\text { SOURCES } \\
\left(\mathbf{Z}_{\mathbf{2}}\right) \text { Km }\end{array}$ \\
\hline 1 & $5.00-5.15$ & $12.45-13.00$ & 2.00 & 0.29 \\
\hline 2 & $5.15-5.30$ & $12.45-13.00$ & 1.61 & 0.30 \\
\hline 3 & $5.00-5.15$ & $12.30-12.45$ & 1.45 & 0.26 \\
\hline 4 & $5.00-5.30$ & $12.30-12.45$ & 1.72 & 0.29 \\
\hline 5 & $5.30-5.45$ & $12.45-13.00$ & 1.30 & 0.32 \\
\hline 6 & $5.45-6.00$ & $12.45-13.00$ & 1.52 & 0.27 \\
\hline 7 & $5.30-5.45$ & $12.30-12.45$ & 1.61 & 0.26 \\
\hline 8 & $5.45-6.00$ & $12.30-12.45$ & 1.34 & 0.29 \\
\hline 9 & $5.00-5.15$ & $12.15-12.30$ & 1.45 & 0.29 \\
\hline 10 & $5.15-5.30$ & $12.15-12.30$ & 1.56 & 0.30 \\
\hline 11 & $5.00-5.15$ & $12.00-12.15$ & 2.30 & 0.25 \\
\hline 12 & $5.15-5.30$ & $12.00-12.15$ & 1.52 & 0.28 \\
\hline 13 & $5.30-5.45$ & $12.15-12.30$ & 1.87 & 0.25 \\
\hline 14 & $5.45-6.00$ & $12.15-12.30$ & 1.75 & 0.26 \\
\hline 15 & $5.30-5.45$ & $12.00-12.15$ & 1.89 & 0.29 \\
\hline 16 & $5.45-6.00$ & $12.00-12.15$ & 1.35 & 0.25 \\
\hline & AVERAGE DEPTH & $\mathbf{1 . 8 6}$ & $\mathbf{0 . 2 8}$ \\
\hline & & & & \\
\hline
\end{tabular}

It is observed that the deep anomaly source depths averaging $1.86 \mathrm{~km}$ represent the basement while the other depth of $0.28 \mathrm{~km}$ by average suggest that they are the intrusions into the sediments in the study area. This result is an improvement on that observed by Umego (1990) wherein the depths the basement was in the range of 1.2 to $2.0 \mathrm{~km}$. According to Wright et al. (1985), the concealment of oil formation from organic remains would be $2.3 \mathrm{~km}$. Based on the values obtained so far from the magnetic analysis; the average depth of the basin is $1.86 \mathrm{~km}$. This depth is very shallow to the basement hence, the results suggests invariably that there is likelihood of lack of hydrocarbon accumulation potential of the study area. Thus, the 
interpreted results which fall short of this expectation showing shallow depth to basement for hydrocarbon accumulation, indicates that the prospect for oil and gas in the area is not feasible.

\section{Conclusions}

The maximum thickness of the sedimentary layers in the basin $(1.86 \mathrm{~km})$ is comparatively less than the minimum depth required for the accumulation of hydrocarbon accumulation at West Africa region. The results of spectral depth analysis using the power spectrum of the residual magnetic anomalies of the Sokoto sedimentary basin are considered reliable having the models detailed into 16 model block. The results obtained from the spectral depth analysis have given a fair idea of depression limit on the basement surface of the basin. Consequently, the analysis invariably points to the fact that the exploration of hydrocarbon would require more sedimentation, increment of temperature and pressure on developing fossils on the given the study area for the hydrocarbon exploration therein to be feasible. 


\section{References}

Dobrin, M. (1981). Introduction to Geophysical Prospecting. McGraw Hill Book Co. $3^{\text {rd }}$ Edition, New York. US. PP. 857

Corell, L. and Grouch, V.J.S. (1985), Mapping basement zones from magnetic data in the san juan basin; New Mexico: presented

Keary, P. and Brooks, M (1984). An introduction to Geophysical Exploration, ELBS (English Language Book Society). Blackwell scientific publications.

Nwogbo, P.O., (1987). Spectral Analysis and Interpretation of aeromagnetic anomalies over Upper Benue Trough, Nigeria. Unpublished M.Sc Thesis, Ahmadu Bello University, Zaria, Nigeria.

Spector, A and Grant, F.S, (1970): Statistical Models for Interpreting Aeromagnetic Data.

Geophysics 35: 293-302

Umego M.N (1990). Structural interpretation of Gravity and magnetic anomalies over sokoto Basin. North-western Nigeria. Unpublished Ph.D Thesis Ahmadu Bello University, Zaria, Nigeria.

Wright, J. B. Hastings D.A. Jones, W.B. and Williams. H.R. (1985). Geology and Mineral resoures of West Africa. George Allen and Urwin, London, 90 -120. 